\begin{tabular}{|c|c|c|c|c|c|}
\hline RSP & $\mathbf{E}$ & $\mathbf{N}$ & 8 & $\mathbf{A}$ & I \\
\hline
\end{tabular}

\title{
- Mercosul no contexto DA INTEGRAÇÃo REGIONAL
}

\section{Clarice Pechman}

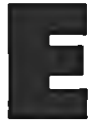

u hoje tenho uma visão muito definida com relaçāo à modificaçāo que houve nos anos 80 , $\mathrm{cm}$ particular nessa primeira metade dos anos 90 , no que se refere ao que diferencia as nações comparativamente a uma situação anterior da década de 60, década de 70 e até um pouco a própria década de 80. Acho que hoje temos uma competição crescente entre as empresas $\mathrm{e}$ as naçōes. E isso não diz respeito apenas a empresas brasileiras, no Brasil e no exterior, mas diz respeito a empresas de toda natureza, quer de serviços, quer industriais, quer se tratem de países de primeiro mundo, quer se tratem de naçōes menos desenvolvidas. Entâo, cu tenho a impressão de que a competição crescente entre empresas e naçōes é alguma coisa que passou a ser a tônica do cenário internacional.

Um outro fato também muito importante é a questão da aceleração do progresso técnico. Quer dizer, na tentativa que houve das empresas escaparem do longo ciclo de

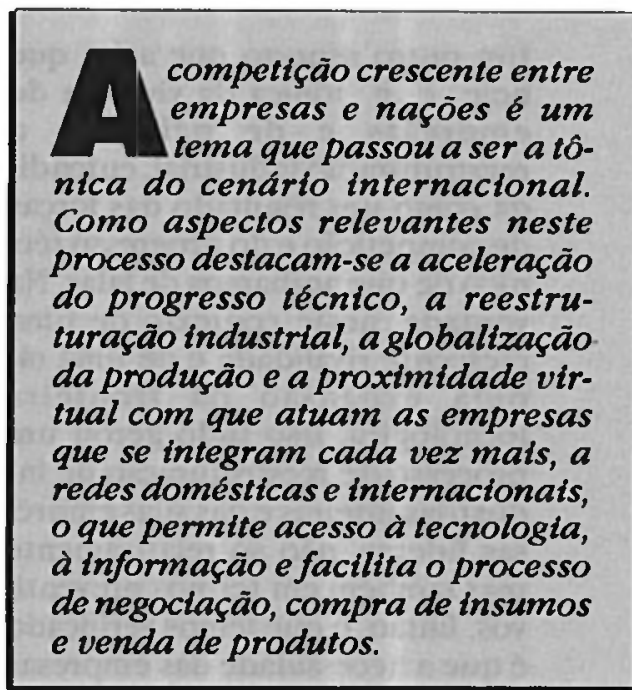

recessão e de retomadas muito hesitantes nos últimos 20 anos, tanto as empresas quanto os países elegeram o progresso técnico como o instrumento preferencial de competição. Então, foi nessa ótica de maior progresso técnico que houve um direcionamento de esforços. Portanto, verificou-se um grande direcionamento de recursos e de esforços em Pesquisa e Desenvolvimento dentro das empresas, bem como para outras atividades, como programas orientados para a redução de custos, para a melhoria de qualidade dos bens que são oferiados e dos serviços 
prestados ao cliente. E o resultado desse esforço dos últimos 20 anos, de crescente progresso técnico, tem sido a rápida introdução de novos produtos, com ciclos cada vez mais curtos e ganhos substanciais e contínuos nos processos de produção.

Um outro aspecto que acho que hoje é a tônica da vivência de empresas e de países é a reestruturação industrial, entendida como um resultado das forças de competição e do progresso técnico de que acabamos de falar. Na verdade, neste contexto de uma crescente rivalidade e de uma rápida expansão da fronteira tecnológica, isso tudo gerou um processo de reestruturação de indústrias inteiras e das suas empresas líderes, não só relativamente mas também em termos preventivos. Então, o que temos verificado é que a necessidade das empresas de incrementar a produtividade, de melhorar a qualidade, de estreitar a relação com os clientes e de auferir rendas de inovaçāo levou as empresas e países, mediante suas lideranças empresariais, a realizar basicamente três níveis de ação. Primeiro, intemacionalizar as suas operações. Nesse sentido, enquanto os fluxos de investimento estrangeiro direto, produçâo e investimento doméstico cresceram a taxas semelhantes nos anos 70 , já no início da década de 80 essas taxas de crescimento $\mathrm{em}$ relação ao PIB começaram a divergir. O que aconteceu foi o seguinte: houve uma tendência crescente à internacionalização das operações das empresas desde 1985 e, a partir daí, o investimento produtivo externo tem crescido a uma taxa quatro vezes superior à taxa de crescimento do PIB mundial, e duas vezes e meia mais do que o crescimen to das próprias exportaçōes, e duas vezes mais rápido do que o investimen to doméstico. Isso dá conta da internacionalizaçāo das operaçōes dos grupos empresariais.

A segunda vertente sobre que comentava é a globalizaçâo da produçao. Passou-se a globalizar a produção, ou seja, esse processo explica a expansão rápida das exportaçōes de manufaturados, cujo crescimento foi mais do que uma vez e meia superior à taxa de expansão da produção doméstica. Em particular, o comércio das empresas multi- nacionais, de um pais para o outro, foi responsável nos últimos anos por aproximadamente $25 \%$ do comércio internacional. Isso é globalizar a produçâo.

Finalmente, a terceira vertente, a que essas consideraçōes iniciais nos levam, é a adoção de um modelo ou de um paradigma chamado pós-fordista, de estruturar a produção e de organizar a empresa. O que está se querendo dizer com isso? Basicamente são duas coisas: a primeira é um novo padrão de produção emergindo na economia intemacional, caracterizado por empresas crescentemente descentralizadas, por cínpresas especializadas horizon- 
talmente com padrōes universalmente rígidos de produtividade, de qualidade, tempo de entrega e de apoio e relação direta com os clientes. A unidade de proxlução hoje é menos hierárquica, mais compacta, com um número menor de níveis entre a administração superior $c$ os trabalhadores de linha - o chão da fábrica. A informação flui de uma mancira mais livre no interior da empresa, sem as retrancas que eram tão comuns nas décadas de 70 e 80 entre os níveis. Os trabalhadores, ou hoje como sāo chamados os associados, isoladamente, e mais comumente em grupos, em círculos, estão ganhando poder para decidir dentro das empresas, sem interferência ou com muito menos interferência de escalóes intermediários. O objetivo é fazer reduzir custos. O objetivo é aumentar a produtividade. É melhorar a qualidade no interior da planta industrial. Nenhum assunto ou área dentro da atividade empresarial hoje é tabu. Isso deixou de existir. Essta é uma nova realidade. Nem mesmo a maneira como a gerência superior conceitua e administra a produção é tabu. É a isso que eu estou chamando de paradigma pós-fordista.

O outro lado da história é a questão da proximidade virtual. São as redes. Ao mesmo tempo, as empresas estão se integrando a redes domésticas e redes internacionais. Por meio dessas redes as empresas têm acesso à tecnologia, acesso à informação, compram insumos que são críticos no âmbito da produção e do controle, e vendem o seu produto. Em paralelo, as firmas estabelecem alianças que chamo de alianças estratégicas, cooperando para poder justamente competir de modo mais eficaz, atendendo ao seu objetivo estratégico, como a minimização de custos. Essa proximidade virtual com fornecedores, com clien tes e mesmo com o governo está orientando hoje as decisōes de in vestimento, as relaçóes contratuais e as novas parcerias govemo-empresa. Em suma, o que posso dizer com relação à reestruturação industrial enquanto resultado da competiçāo e do progresso técnico, é que essas forças econômicas que marcaram a última década, ou seja, competição, progresso técnico e reestruturação, geram poderosas correntes que estão impulsionando as empresas no sentido da sua intemaciona- lização, no sen tido da globalização e no sentido da adoção de modelos radicalmente distintos de gerência (management) e de produção. Essas tendências estão forçando os analistas a repensar o sentido, o conteúdo de um projeto nacional de desenvolvimento industrial, e a indagar qual o papel do Estado no novo contexto de desenvolvimento, no novo contexto de disputa crescente, $\mathrm{c}$ de expansão rápida da fronteira tecnológica. Tudo o que hoje é ponta tecnológica, amanhã pơde perfeitamente não ser mais. E os empreendimentos têm que ter uma capacidade, uma dinâmica de 
readaptaçāo continua que exige essa gerência, digamos assim, quase que no chão de fábrica. A gestão tcm que dar poder decisório a instâncias onde seria inadmissivel há muito tempo atrás. Isso é uma verdadeira revolução.

Em particular, hoje temos uma questão mundial de redefinir política industrial. Ou de redefinir efetivamente política industrial. Porque não nos serve muito olhar para o passado para alcançar uma definiçāo que esteja compativel com essas mudanças todas que acabei de descrever de maneira evidentemente muito sucinta. E, nisso tudo, o que estamos vendo, e aí eu vou especificamente ao caso do Brasil, é de que estamos hoje trabalhando, ou pelo menos temos que trabalhar, por uma indústria competitiva, por uma indústria integrada na economia mundial, por uma indústria crescentemente povoada por $\mathrm{cm}$ presas que utilizam intensamente o trabalho quali- ficado produzindo, via processos eficientes e limpos, bens de alto valor agregado e com capacidade sustentada de criação de emprego. Uma configuraçâo dessa natureza que acabei de descrever iria se refletir num aumento pronunciado da produtividade de recursos humanos e, conseqüentemente, num substancial aumento da renda e do consumo da população. $\mathrm{Na}$ verdade, isso é um moto perpétuo. fo ovo e a galinha! Precisase de renda, portanto precisa-se que as pessoas estejam bem remu- neradas para que tenham renda para consumir, e para que esse consumo gere produção, para que essa produçâo esteja empenhada, sob um ambiente de estabilidade, no desenvolvimento do produto, no desenvolvimento da engenharia do produto, no desenvolvimento do marketing do produto e nāo no desenvolvimento de um arremedo de política que gera uma concentração absolutamente ab. surda e desequilibrada dos esforços criativos empresariais numa área financeira administrativacontábil como é, hoje, em vista de uma desestabilização inflacionária com a qual convivemos há longo tempo.

As consideraçōes que fiz aqui são de natureza geral, embora organizadas. E quero fazer um parênteses. Eu me referi especificamente à indústria, muito embora houvesse uma crença até há pouco tempo de que resolveríamos todos os problemas do mundo saindo da indústria, do desenvolvimento manufatureiro para o desenvolvimento de serviços. $O$ argumento, sendo o de que não teríamos tanta dificuldade de estar na ponta do conhecimento, porque não é um setor que exija tanta tecnologia, este de serviços comparativamente à indústria. Ao mesmo tempo, seria um setor altamente empregador de mão-de-obra. O fato é que a verdade está um pouco longe do que se imaginava. O setor de serviços, em última instância, provou isso com base na experiência internacional dessa última década - li- 
mitado na sua possibilidade de render crescimento para o país. Ele, em última instância, precisa ser revigorado periodicamente pelo desenvolvimento da atividade industrial. Assim, é da atividade industrial que emerge, digamos, o motor do desenvolvimento nacional como um todo. E é nesse sentido que eu volto a minha atenção, no sentido da internacionalização, da globalizaçāo e da regionalizaçāo para a área industrial mais do que qualquer outra, porque é aí que está o cerne do desenvolvimento. Creio que os esforços de internacionalizaçâo e, portanto, para a formação de blocos econômicos, o esforço do Brasil na integração do MERCOSUL especificamente, devem contemplar as questões aqui abordadas que, embora genéricas, conceitualizam o mundo da virada desse século. Portanto, $a$ internacionalização deve priorizar investimento em qualificação, em educaçāo. O retorno social do investimento em educação tem se mostrado substancialmente maior do que os outros tipos de investimento, para garantir o salto de que hoje estamos precisando; o Brasil em particular, e o mundo como um todo, nas suas relaçōes internacionais do intercâmbio, quer se trate de investimentos diretos, quer se trate de comércio propriamente dito. Precisamos desse salto, e ele depende do atributo de qualificação da mão-de-obra até porque ficou provado, também, que essa renovação no âmbito da tecnologia, do progresso técnico e da reestruturação industrial, tanto a reestruturação preventiva quanto a reestruturação ativa, não tenha capacidade de reabsorver mão-de-obra que foi, ao longo da década de 80, expelida do processo. A partir da recessão de 1980 , houve uma taxa de desemprego crescente. Todas as estatísticas com relação a desemprego nos mostram a sua tendência crescente, o fenômeno não é só brasileiro. O que mostra o seguinte: que apesar desses saltos que o progresso técnico, a reestruturação industrial, a globalização da economia, a in temacionalização, os blocos económicos, nâo fomos capazes de recuperar o status quo no que se refere à taxa de desemprego. Ou seja, nâo conseguimos fazer com que o aumento de emprego recuperasse aqueles que se viram desempregados, ou desse posto de trabalho, devidamente remunerado, aos novos que estão se oferecendo no mercado. Existem sim, a partir desses surtos novos, acréscimos de nível de emprego. Mas apenas marginais. Não no nível que fizesse com que a taxa de desemprego descesse ao que era ao final da década de 70. Esta é uma realidade internacional. No âmbito da internacionalização, da globalização da economia, temos que dar prioridade a uma estrutura nova empresarial - provavelmente de pequenas e médias empresas, que são empregadoras de mão-de-obra - para que consigamos de alguma maneira minimizar e tratar de uma forma coerente, do 
ponto de vista da política econômica, o conflito que existe entre a reestruturação industrial de um lado e o aumento da taxa de desemprego por outro. Fixiste esse conflito. A experiência internacional inequivocamente o evidencia. Prova que as empresas estão trabalhando em termos de menores custos, de melhor qualidade de produto, de um relacionamento maior com o fornecedor, um relacionamento melhor, mais presente, mais participativo com o cliente, um enxugamento da estrutura com a redução dos níveis hicrárquicos. Mas isso conflita com as taxas de desemprego que estão crescendo ao longo do tempo, e irāo continuar a crescer se não dermos prioridade $e$ incentivarmos, no âmbito empresarial de cada pais ou dos blocos, internacionalmente falando, as empresas que são mais capazes de empregar.

\section{Resumen}

EL MERCOSUR EN EL

CONTEXTO DE LA INTEGRACIÓN REGIONAL

La creciente competencia entre empresas y naciones es un tema que ha pasado a ser la tónica del escenario internacional. Como aspectos relevantes en este proceso se destacan la aceleración del progreso técnico, la reestruturación industrial, la globalización de la producción y la proximidad virtual con que actúan las empresas que se integran cada vez más a redes domésticas y intemacionales, lo que permite acceso a la tecnología, a la información y facilita el proceso de negociación, compra de insumos y venta de productos.

\section{Absiract \\ MERCOSUL IN THE REGIONAL INTEGRATION CONTEXT}

The growing competition among nations and companies is a theme that has become the center of intemational scenario. As relevant aspects in this process we can underscore: the accelaration of tecnical progress, industrial reorganization, the globalization of production and the virtual proximity with which the companies that are integraing more and more are working, domestic and international networks that permit the access to tecnology and information and help in the negotiation process, purchase of input and negotiation of products.

Texto baseado em palestra proferida durante o Encontro Nacional: Função Pública, Estado e Sociedade, realizado na INAP, Brasília/DF, em abril de 1994.

Clarice Pechoman é diretora executiva da Associação Nacional de Empresas Credenciadas em Câmbio - ANECC. 